\title{
NON LINEAR OPTICAL PROPERTIES OF BOROPHOSPHATE GLASSES
}

\section{E.FARGIN}

Institut de Chimie de la Matière Condensée de Bordeaux , UPR CNRS 9048, Avenue du Dr. Schweitzer, 33608 PESSAC France.

Abstract The non linear optical properties of glasses are investigated with the object of potential applications as optical devices e.g. amplification and modulation of light, parametric frequency conversion, ultra-fast switching etc. By combining structural, optical and theoretical studies the origin of the third-order optical response has been determined in sodium calcium borophosphate glasses containing increasing proportion of $\mathrm{TiO}_{2}$ or $\mathrm{Nb}_{2} \mathrm{O}_{5}$. The values of the third-order susceptibility $\chi^{(3)}$ can be analysed on the basis of the bond orbital theory and are directly related to the $\mathrm{Ti} / \mathrm{Nb}$ d-orbital contributions. For the richest titanium and niobium glasses the clustering of $\mathrm{TiO}_{\mathrm{n}}(\mathrm{n}=5,6)$ or $\mathrm{NbO}_{6}$ entities tends to increase leading to an enhancement of the non linear index $n_{2}$. More recently Second Harmonic Generation (SHG) has been observed when these glasses were subjected to a dc bias of $3 \mathrm{kV}$ at $300^{\circ} \mathrm{C}$. The close examination of the glasses surfaces before and after poling brings new ideas about the microscopic origin of this phenomenon.

\section{INTRODUCTION}

Non-linear optical properties of transparent materials are at this time the focus of growing interest for elaboration of all-optical devices, such as photonic modulators, optical data storage and telecommunication, or for the spectral extension of laser sources ${ }^{1}$. The recent discovery of Second Harmonic Generation (SHG) in glasses after poling treatment (the glass beeing inserted between two electrodes and submitted to high d.c. field) and/or under high energy radiation induces new development related to new functional integrated devices ${ }^{2,3}$. Basically, the nonlinear optical properties of materials under an electromagnetic field $\mathrm{E}$ result from the generation of a polarisation $\mathrm{P}$, which can be expressed as a power series in $\mathrm{E}: \mathrm{P}=\chi^{(1)}+\chi^{(2)} \mathrm{E} . \mathrm{E}+\chi^{(3)}$ E.E.E $+\ldots$. where $\chi^{(1)}$ is the linear susceptibility which accounts for the linear optical index, $\chi^{(2)}$ (responsible for SHG, $\chi^{(2)}=0$ in glasses)and $\chi^{(3)}$ (responsible for nonlinear indices $\mathrm{n}_{2}$ ) 
correspond respectively to the second and third order nonlinear susceptibilities. The choice of the glass composition is dictated by the necessity of increasing $n_{2}$ but various other parameters must be considered e.g. irradiation damage threshold, ability to device realization such as wave-guides or fiber etc. From theoretical considerations ${ }^{4}$ and previous experiments ${ }^{1}$ the intensity of $n_{2}$ increases with the introduction of $\mathrm{d}^{0}$ ions $\left(\mathrm{Ti}^{4+}\right.$, $\mathrm{Nb}^{5+}$ ) giving rise to high hyper-polarizable (Ti-O)n or $(\mathrm{Nb}-\mathrm{O})$ n entities. Moreover, the third order nonlinearity has been involved in the SHG mechanism through a coupling with the internal dc field generated inside the glass during poling ${ }^{2,3}$. The present paper reviews recent results obtained for glasses with the following compositions (1-y) [0.95 $\left.\mathrm{NaPO}_{3}, 0.05 \mathrm{Na}_{2} \mathrm{~B}_{4} \mathrm{O}_{7}\right]$ y $\mathrm{TiO}_{2}$ (resp. $\mathrm{Nb}_{2} \mathrm{O}_{5}$ ) and (1-y) $\left[0.9 \mathrm{Ca}\left(\mathrm{PO}_{3}\right)_{2}, 0.1 \mathrm{CaB}_{4} \mathrm{O}_{7}\right]$ y $\mathrm{Nb}_{2} \mathrm{O}_{5}$. The great stability of the sodium or calcium borophosphate matrix glasses allowed the introduction of large quantities of highly nonlinear $\mathrm{TiO}_{2}$ and $\mathrm{Nb}_{2} \mathrm{O}_{5}$ oxides $^{5,6}$.

(i) The $\chi^{(3)}$ values will be explained by coupling a structural investigation with a theoretical analysis by applying to glasses the bond orbital theory of M. E. Lines ${ }^{4}$.

(ii) The origin of the SHG observed in some of these glasses submitted to a poling treatment will be discussed after a detailed investigation of the glass surfaces in contact with the electrodes.

\section{EXPERIMENTAL PROCEDURE}

The elaboration procedures for these glasses (classical melting of mixed oxides, air quenching and annealing) have been previously described ${ }^{5-7}$.

The linear and nonlinear indices have been measured by the use of a MachZehnder interferometer ${ }^{8,9}$. The laser source is a TiSa oscillator (resp. an OPO pumped by a TiSa oscillator) delivering polarized pulses of $150 \mathrm{fs}$ at $840 \mathrm{~nm}$ (resp. $1.5 \mu$ ). The $\mathrm{SH}$ signal is measured in transmission through the poled calcium borophosphate glasses (poling conditions: d.c. bias $=3 \mathrm{kV}, \mathrm{T}=300^{\circ} \mathrm{C}$ during one hour). A TiSa oscillator (resp. $\mathrm{Nd}$ :YAG laser) is used for measurements at around 800nm (resp. 1.06 $\mu$ ).

Structural characterizations were obtained by RAMAN, XAFS, XPS and FTIR spectroscopies. RAMAN, XAFS and XPS experimental analysis have been largely described $^{7,10,11}$. FTIR analysis has been used for poled calcium borophosphate 
characterization: IR reflectance experiments were performed using an external reflection attachment (Grosegy, Specoc) at an angle of incidence of $12^{\circ}$. The extinction coefficient can be calculated from the reflectance spectra by the Kramers-Kronig analysis. Structural modifications after poling can be evidenced by calculating the substraction between the poled anode or cathode face reflectance signal and the corresponding unpoled face signal.

\section{RESULTS AND DISCUSSION}

(i) Nonlinear indices and $\chi^{(3)}$ measurements at around $840 \mathrm{~nm}$ and $1.5 \mu$ are given on table 1 . For each wavelength, the nonlinear efficiency is increasing with the ratio of $\mathrm{Nb}_{2} \mathrm{O}_{5}$ or $\mathrm{TiO}_{2}$. This was effectively expected for $\mathrm{d}^{0}$ cations like $\mathrm{Nb}^{5+}$ and $\mathrm{Ti}^{4+}$ are wellknown to polarize electronic clouds of oxygen in metal-ligand bonding formation ${ }^{4}$. Contrary to other glass systems containing niobium and titanium oxides, $\chi^{(3)}$ is not linear with the concentration of metallic cations in the glass but an enhancement of the nonlinear efficiency is observed (FIGURE 1.a, 1.b). This allowed our borophosphate glasses to reach an efficiency comparable to the commercial SF59 for the largest concentration in niobium. The theory of LINES has been successfully extended to our glasses by the use of $\mathrm{Ti}-\mathrm{O}$ and $\mathrm{Nb}-\mathrm{O}$ bonding parameters ${ }^{4}$ related to RAMAN and XAFS structural characterizations of metal-oxygen sites in glasses ${ }^{10-11}$. Experimental macroscopic linear and nonlinear indices are in accordance with the calculated values using the Lines parameters, in so far oxygenated sites are isolated in the glass. An enhancement of the nonlinear $\chi^{(3)}$ response for the highest metal concentrations is observed when compared to the $\operatorname{model}^{8}$ (FIGURE 1.a, 1.b). It has been related to the formation of KTP-like Ti-O-Ti chains or three dimensional Nb-O framework ${ }^{8,10,11}$.

(ii) SHG has been evidenced in poled calcium borophosphate glasses ${ }^{7}$ (table 2). After optimization of the glasses efficiency, the $\chi^{(3)}$ value cannot clearly be involved in the glass response which remains inferior to the Vitreosil or Herasil silica glass response. The nonlinearity has been proved to be localized near the surfaces in contact with electrodes during the poling treatment ${ }^{7}$, whereas an accumulation of sodium cations to the cathodic surface has been unambiguously observed by XPS spectroscopy $^{12}$. 
TABLE 1 Nonlinear index results

\begin{tabular}{|c|c|c|c|c|c|c|}
\hline \multirow[b]{2}{*}{ compound } & \multicolumn{3}{|c|}{ Wavelength: $840 \mathrm{~nm}$} & \multicolumn{3}{|c|}{ Wavelength: $1.5 \mu$} \\
\hline & $\begin{array}{c}\mathrm{n}_{0} \\
\pm 0.02\end{array}$ & $\begin{array}{c}\mathrm{n}_{2} \\
10^{19} \mathrm{~m}^{2} / \mathrm{W} \\
\pm 10 \%\end{array}$ & $\begin{array}{c}\chi^{(3)} \\
10^{21} \mathrm{~V}^{2} / \mathrm{m}^{2} \\
\pm 10 \%\end{array}$ & $\begin{array}{c}\mathrm{n}_{0} \\
\pm 0.02\end{array}$ & $\begin{array}{c}\mathbf{n}_{2} \\
10^{19} \mathrm{~m}^{2} / \mathrm{W} \\
\pm 10 \%\end{array}$ & $\begin{array}{l}\chi^{(3)} \\
10^{21} \mathrm{~V}^{2} / \mathrm{m}^{2} \\
\pm 10 \%\end{array}$ \\
\hline $\mathrm{BPNa}^{*}-13.9 \% \mathrm{TiO}_{2}$ & 1.59 & 1.6 & 0.8 & & & \\
\hline $\mathrm{BPNa}-26.3 \% \mathrm{TiO}_{2}$ & 1.65 & 3.0 & 1.4 & 1.65 & 1.08 & 0.52 \\
\hline $\mathrm{BPNa}-33.3 \% \mathrm{TiO}_{2}$ & 1.72 & 4.1 & 2.2 & 1.72 & 1.62 & 0.85 \\
\hline $\mathrm{BPNa}-42.2 \% \mathrm{TiO}_{2}$ & 1.80 & 6.9 & 4.0 & 1.75 & 2.23 & 1.21 \\
\hline BPNa-11.3\% $\% \mathrm{Nb}_{2} \mathrm{O}_{5}$ & 1.61 & 2.2 & 1.0 & & & \\
\hline $\mathrm{BPNa}-30 \% \mathrm{Nb}_{2} \mathrm{O}_{5}{ }^{* *}$ & & & & 1.77 & 2.06 & 1.14 \\
\hline $\mathrm{BPNa}-37.0 \% \mathrm{Nb}_{2} \mathrm{O}_{5}$ & 1.84 & 5.2 & 3.1 & & & \\
\hline $\mathrm{BPNa}-43.0 \% \mathrm{Nb}_{2} \mathrm{O}_{5}$ & 1.96 & 8.0 & 5.4 & & & \\
\hline BPNa matrix glass & 1.48 & 0.9 & 0.4 & & & \\
\hline $\mathrm{BPCa}^{*}$ matrix glass & 1.56 & 0.86 & 0.37 & 1.57 & 0.05 & 0.02 \\
\hline $\mathrm{BPCa}-20 \% \mathrm{Nb}_{2} \mathrm{O}_{5} * *$ & 1.67 & 2.4 & 1.2 & 1.66 & 1.61 & 0.79 \\
\hline $\mathrm{BPCa}-30 \% \mathrm{Nb}_{2} \mathrm{O}_{5} * *$ & 1.76 & 3.8 & 2.1 & 1.71 & 2.35 & 1.21 \\
\hline Herasil silica glass & 1.46 & 0.72 & 0.27 & 1.47 & 0.12 & 0.05 \\
\hline SF59 & 1.97 & 9.0 & 6.2 & 1.88 & 4.50 & 2.80 \\
\hline
\end{tabular}

*BPNa for $0.95 \mathrm{NaPO}_{3}, 0.05 \mathrm{Na}_{2} \mathrm{~B}_{4} \mathrm{O}_{7}$ and $\mathrm{BPCa}$ for $0.9 \mathrm{Ca}\left(\mathrm{PO}_{3}\right)_{2}, 0.1 \mathrm{CaB}_{4} \mathrm{O}_{7}$.

**theoretical concentrations (all other compositions have been checked)

TABLE 2 Second-Harmonic Generation Intensity recorded on glass samples poled at $300^{\circ} \mathrm{C}$ and $3 \mathrm{kV}$

\begin{tabular}{|c|c|c|}
\hline $\begin{array}{c}\text { Glass } \\
\text { sample }\end{array}$ & $\begin{array}{c}\text { SHG signal (a.u.) } \\
\text { at } 800 \mathrm{~nm}\end{array}$ & $\begin{array}{c}\text { SHG signal (a.u.) } \\
\text { at } \mathbf{1 . 0 6 4} \mu *\end{array}$ \\
\hline Fused vitreosil silica glass & 100 & 100 \\
\hline $\mathrm{BPCa}$ matrix glass & 1.5 & 25 \\
\hline $\mathrm{BPCa}-10.0 \% \mathrm{Nb}_{2} \mathrm{O}_{5}$ & 6 & \\
\hline $\mathrm{BPCa}-20.0 \% \mathrm{Nb}_{2} \mathrm{O}_{5}$ & 12 & 26 \\
\hline $\mathrm{BPCa}-30.0 \% \mathrm{Nb}_{2} \mathrm{O}_{5}$ & 16 & \\
\hline
\end{tabular}

*The SHG response has been optimized by a cycling poling-depoling procedure ${ }^{12}$ 




$\chi$ (3) values for the titanium borophosphate glasses.

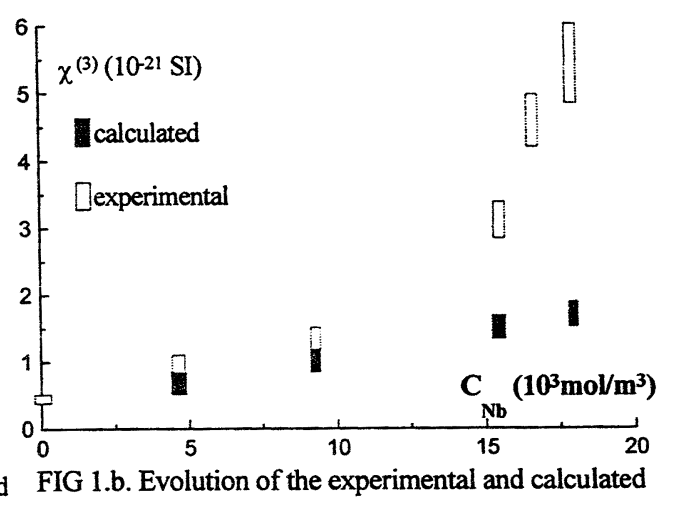

$\chi^{(3)}$ values for the niobium borophosphate glasses.

Moreover, an interesting decrease of the signal under irradiation at $800 \mathrm{~nm}$ has been characterized ${ }^{13}$. The creation of charge carriers inside the glass under irradiation, diffusing to the surfaces and neutralizing the charges accumulated under poling has been involved.

RAMAN, XAFS and XPS structural characterizations showed a progressively opening of the borophosphate network when introducing increasing proportions of niobium oxide, with the appearance of more non-bridging oxygen atoms. A comparable procedure is evidenced by XAFS and XPS on the anodic surface of a given composition when it is poled. After a thermal treatment during which the SHG is erazed, the bridging bonds are restored ${ }^{12}$. IR reflectance measurements show a slight but significant difference between poled and unpoled surfaces signals in the 960 to $1150 \mathrm{~cm}^{-1}$ region(FIGURE 2). The corresponding transitions are attributed to symmetrical and antisymmetrical vibration modes of terminal $\left[\mathrm{PO}_{3}{ }^{-}\right]$groups on phosphate chains constituting the glass network. The decrease of the signal in this domain can be explained by an orientation of these groups perpendicularly to the anodic surface if the glass. On the basis of these results, the breakdown of isotropy induced by poling is evidenced. Whether such alterations can account for the measured SHG efficiency in niobium borophosphate glasses needs to be clarified. Ab-initio calculations under investigation could provide promising information. 


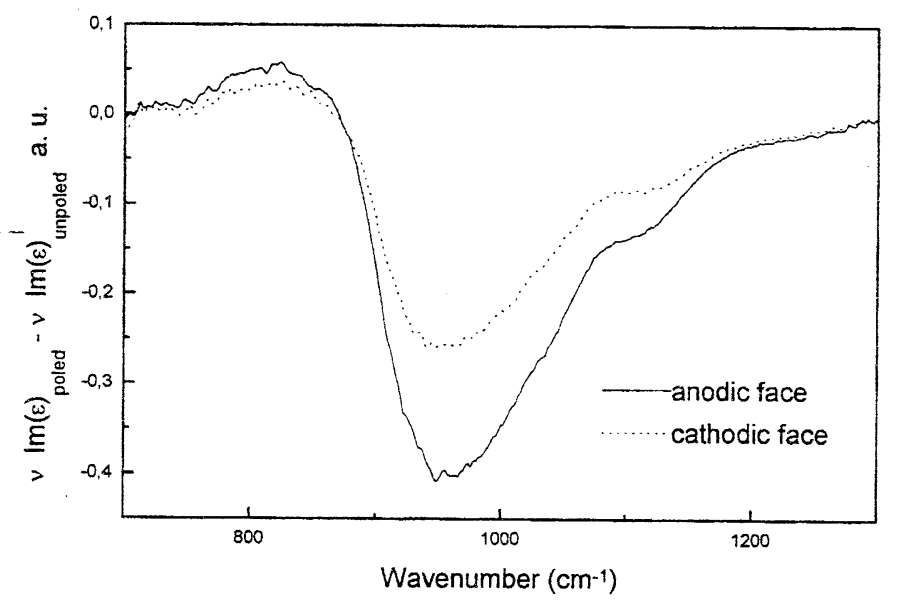

FIGURE 2. Substraction of the IR reflectance signal of poled anode
or cathode surface from the corresponding unpoled surface signal
for the niobium borophosphate glass.

\section{$\underline{\text { SUMMARY }}$}

This paper reviews nonlinear optical properties of sodium or calcium borophosphate glasses containing titanium or niobium oxides. The third order nonlinear efficiency is correlated to the concentration of $d^{0}$ ions in the glass. An enhancement is observed for the highest concentrations of titanium or niobium related to the clustering of $\mathrm{TiO}_{\mathrm{n}}(\mathrm{n}=5,6)$ or $\mathrm{NbO}_{6}$ entities. The second order nonlinear efficiency generated by thermal poling is observed in calcium borophosphate glasses and can be optimized by a cycling process. The nonlinear response is correlative to $\mathrm{Na}^{+}$impurities migration to the cathode during poling, opening of the glass network and reorientations of terminal $\left[\mathrm{PO}_{3}{ }^{-}\right]$groups on phosphate chains near the surface in contact with the anode.

\section{ACKNOLEDGMENT}

Grateful thanks to T. Cardinal, V. Nazabal, G. Le Flem, L. Sarger, S. Leboiteux, P. Segonds, L. Canioni, M. O. Martin; E. Freysz, A. Le Calvez, S. Montand, F. Adamietz, C. Cartier dit Moulin, V. Briois, C. Labrugère, M. Couzi, L. Ducasse, B. Desbat, T. Buffeteau for their contribution to this review paper.

\section{REFERENCES}

1- E. M. Vogel, S. G. Kosinski, D. M. Krol, J. L. Jackel, S. R. Friberg, M. K. Oliver,

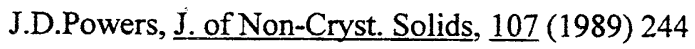


2- R.A. Myers, N. Mukherjee, S.R.J. Brueck, Optics Letters, 16 (1991) 1732-1734.

3- N. Mukherjee, R.A. Myers, S.R.J. Brueck, JOSA B, 11 (1994) 665-669.

4- M. E. Lines, Physical Review B, $\underline{43}$ (1991) 11978

5- T. Cardinal, E. Fargin, G. Le Flem, M. Couzi, L. Canioni, P. Segonds, L. Sarger,

A. Ducasse, F. Adamietz, Eur. J. Solid State Inorg. Chem., 33 (1996) 597

6- T. Cardinal, E. Fargin, G. Le Flem, L. Canioni, P. Segonds, L. Sarger, A. Ducasse,

F. Adamietz, Eur. J. Solid State Inorg. Chem., 31 (1994)

7- V. Nazabal, E. Fargin, J.J. Videau, G. Le Flem, A. Le Calvez, S. Montant, E.

Freysz, A.Ducasse, M. Couzi, J. of Solid State Chem, 133 (1997) 529-535.

8- S. Le Boiteux, P Segonds, L. Canioni, L. Sarger, T. Cardinal, C. Duchesne, E. Fargin, G. Le Flem, J. Appl. Phys., 81 (1997) 1481

9- B. Jeansannetas, S. Blanchandin, P. Thomas, P. Marchet, J.C. ChamparnaudMesjard, T. Merle-Méjean, B. Frit, V. Nazabal, E. Fargin, G. Le Flem, M. O. Mártin, B. Bousquet, L. Canioni, S. Le Boiteux, P. Segonds, L. Sarger, accepted to J. of Solid

\section{State Chem.}

10- T. Cardinal, E. Fargin, G. Le Flem, M. Couzi, J. of Sol. State Chem., 120 (1995) 151

11-T. Cardinal, E. Fargin, G. Le Flem, S. Leboiteux, J. of Non Cryst. Sol.,22(1997)228

12- V. Nazabal, E. Fargin, C. Labrugère, G. Le Flem, submitted to J. of Non-Cryst. $\underline{\text { Solids }}$

13- S. Montant, E. Freysz, A. Ducasse, V. Nazabal, E. Fargin, G. Le Flem, Applied Physics Letters, 74 (1999)2623 